\title{
Urbanization and its Classification in China from the Consideration of Environment
}

\author{
Xingtian Wang*1, Weijun $\mathrm{Gao}^{2}$, Haifeng $\mathrm{Li}^{3}$, Penglin $\mathrm{Zhao}^{4}$, Jianxing Ren ${ }^{5}$ and Toshio Ojima ${ }^{6}$ \\ ${ }^{1}$ Graduate School, Faculty of Environment Engineering, The University of Kitakyushu, Japan \\ ${ }^{2}$ Associate Professor, Faculty of Environment Engineering, The University of Kitakyushu, Japan \\ ${ }^{3}$ Researcher, Building Research Institute, Japan \\ ${ }^{4}$ Chief Engineer, Shenzhen Municipal Planning \& Land Bureau, P.R.China \\ ${ }^{5}$ Professor, Department of Power Engineering, Shanghai Institute of Electric Power, P.R.China \\ ${ }^{6}$ Professor, Department of Architecture, Waseda University, Japan
}

\begin{abstract}
In this study, the relation of urbanization in China urban areas has been investigated with energy consumption, social economics, infrastructure, transportation and environment. The results showed that the impact of those factors on the urbanization become significant. The deep investigation is needed in clearing the effect of the local development on the urbanization. In this paper, the energy consumption, social economics, infrastructure, transportation/communication and environment have been used as a index to evaluate the importance of the urbanization in China Province with the urbanization area and population. By using the statistical method, the classification of urbanization has been made. As the result, the provinces in China could be divided into the IV classification. Also, the energy index, the infrastructure index, the social economy index increased as to make a city progressed but it found that the environment index fell oppositely from the factor analysis.
\end{abstract}

Keywords: China; urbanization; environment; and classification

\section{Introduction}

Economic growth accelerates the development of city inevitably. At present, the urbanization vitality of the developing country is frightful, and the disorderly development brought about not only the increase of energy consumption but also air pollution and the aggravation of living environment and other serious problems. And in Asia, especially in China, the highspeed economic growth rate has produced great influence on the resources and environment of the world. In this paper, the urbanization and energy consumption in China Province have been investigated, and the issues of urban environment have been clarified.

Moreover, although many evaluations of urbanization have been made from the standpoints of the urban population and the urban area, the increase of population and area of city is affected by many various elements, such as, social economy, energy consumption, infrastructure, etc. But the increase of population and area is just the surface phenomenon of urbanization. In this paper, the energy consumption, infrastructure, environment and so on have been used as the different criterions to evaluate the urbanization of China, based on the statistics data ${ }^{1)}$, which is about 27 provinces

*Contact Author: Xingtian Wang, GAO Laboratory, Faculty of Environment Engineering, The University of Kitakyushu 1-1 Hibikino, Wakamatsu,Kitakyushu, Fukuoka,808-015, Japan Tel.:+81-93-695-3234 Fax: +81-93-695-3335

e-mail: xingtian@hotmail.co.jp

(Received August 30, 2004 ; accepted March 22, 2005)
(Taiwan is not included) and three direct control cities (Beijing, Shanghai, Tianjin), the classification of urbanization in China Province has been made.

\section{Urbanization conditions of each province 2.1 Population}

Fig.1 shows the ratio of the urban population. Although the urban population decreased in the $60 \mathrm{~s}$ for the Cultural Revolution, the urban population ratio began to go up from the 80s sharply, that is because the rapid growth of the economy in China since the government adopting the policy of opening and reform in the late 1970s. The urban population reached about 30 percent of whole 1,200 million populations in 1995 .

\subsection{Urbanization condition}

Fig. 2 shows annual change of the urban area of each province. Compared with the western hinterland, the coastal region has gained remarkable advance of the urbanization in every five years. Especially, in

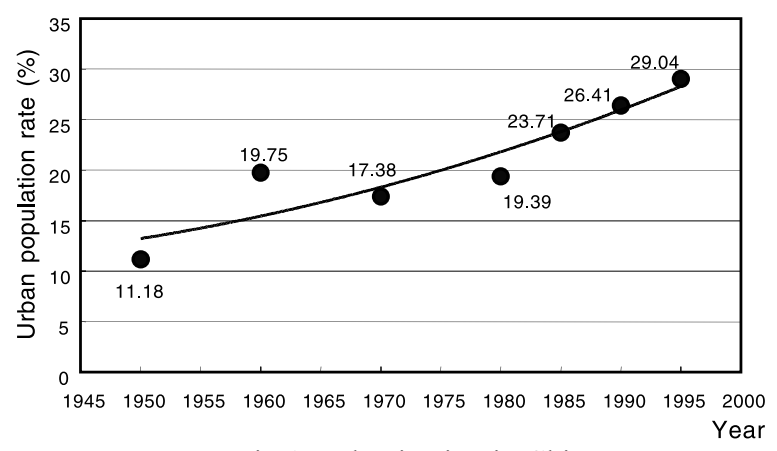

Fig.1. Urbanization in China 


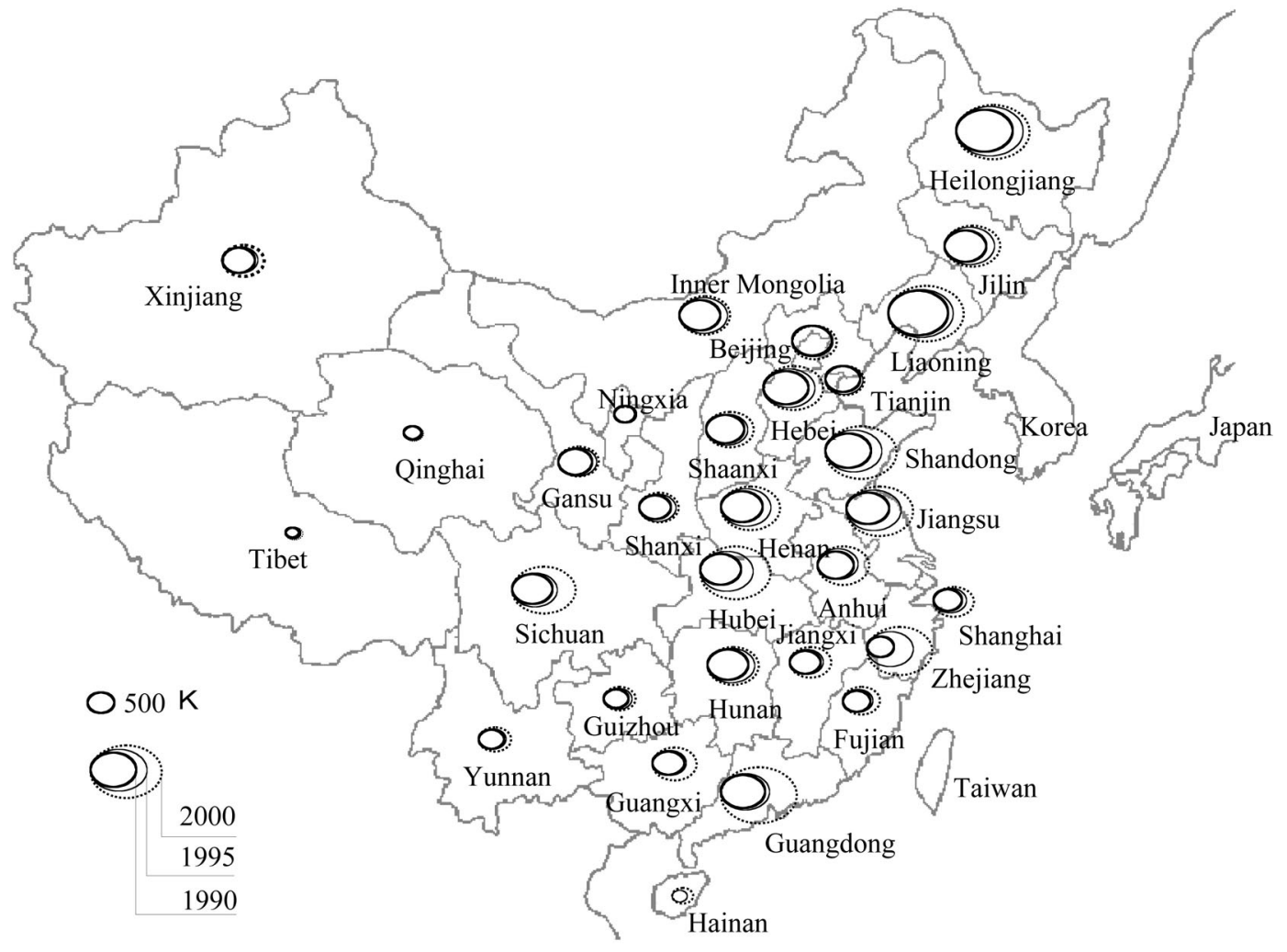

The change of urban area in 1990, 1995, 2000 from inside

Fig.2. The Yearly Change of Urban Area in China

Table 1. Index Related with Urbanization

\begin{tabular}{|l|l|}
\hline \multicolumn{1}{|c|}{ Basic index(j) } & \multicolumn{1}{|c|}{ Item index $(\mathrm{k})$} \\
\hline Urban area & Rate of urban area \\
\hline Urban population & Rate of urban population \\
\hline $\begin{array}{l}\text { Energy } \\
\text { consumption } \\
(\mathrm{k}=8)\end{array}$ & $\begin{array}{l}\text { Coal consumption amount of per capita, } \\
\text { crude oil consumption amount of per capita, } \\
\text { power consumption of per capita for residential } \\
\text { use. }\end{array}$ \\
\hline $\begin{array}{l}\text { Social economy } \\
(\mathrm{k}=4)\end{array}$ & $\begin{array}{l}\text { Gross output value of industry of per capita, } \\
\text { GDP of per capita, } \\
\text { Employment, } \\
\text { Employment of tertiary industry }\end{array}$ \\
\hline $\begin{array}{l}\text { Infrastructure } \\
(\mathrm{k}=11)\end{array}$ & $\begin{array}{l}\text { Length of water supply pipelines of per capita, } \\
\text { Total volume of water supply of per capita, } \\
\text { Total volume of water supply of per capita for } \\
\text { residential use, } \\
\text { Disposal sewage amount of per capita, } \\
\text { Length of sewer pipeline of per capita, } \\
\text { Total road length of per capita, } \\
\text { Paved road Length of per capita, } \\
\text { Total gas supply of per capita for residential use, } \\
\text { Total LPG supply of per capita for residential } \\
\text { use. }\end{array}$ \\
\hline $\begin{array}{l}\text { Mransportation/ } \\
\text { Communication } \\
(\mathrm{k}=4)\end{array}$ & $\begin{array}{l}\text { Telephones of per capita, } \\
\text { Mobile telephone and post office of per capita, }\end{array}$ \\
\hline $\begin{array}{l}\text { Environment } \\
(\mathrm{k}=5)\end{array}$ & $\begin{array}{l}\text { Area of urban park, Percentage of Landscaping, } \\
\text { Waste gas emission, SO2 emission, } \\
\text { Dust discharged. }\end{array}$ \\
\hline
\end{tabular}

Guangdong Province, Hainan Province, and Zhejiang Province, the urban area has been sharply increased compared with 1990.

\section{Classification method}

In this paper, the energy consumption, social economics, infrastructure, transportation/communication and environment have been used as seven indexes including the urban area and population to evaluate the urbanization in China Province. These indexes are shown in table.1. The urbanization progress condition has been evaluated in China Province according to the classification based on the ratio of population density and the urban area.

In order to unify the evaluation base, the following formula was defined.

$$
S_{i j}=\frac{\sum_{k}^{n} \frac{k \text { item index value of } i \text { Province }}{\text { national average value of } k \text { item index }}}{\text { Number of representation items for } j \text { basic index }}
$$

Where,

$\mathrm{S}_{\mathrm{ij}}$ is the urbanization evaluation mark of i Province on $\mathrm{j}$ basic index.

It is noted that the reciprocal of the evaluation mark about items, discharge gas, $\mathrm{SO}_{2}$, and dust have been used to evaluate the environment, because the worse environment can be found when the evaluation mark of discharge gas, $\mathrm{SO}_{2}$, and dust is high.

Furthermore, in this paper, 100 marks are considered as the national average evaluation value. When the evaluation mark exceeded 100 in one region, it can be concluded that the evaluation of this region is better than other regions.

The comprehensive evaluation index of urbanization 


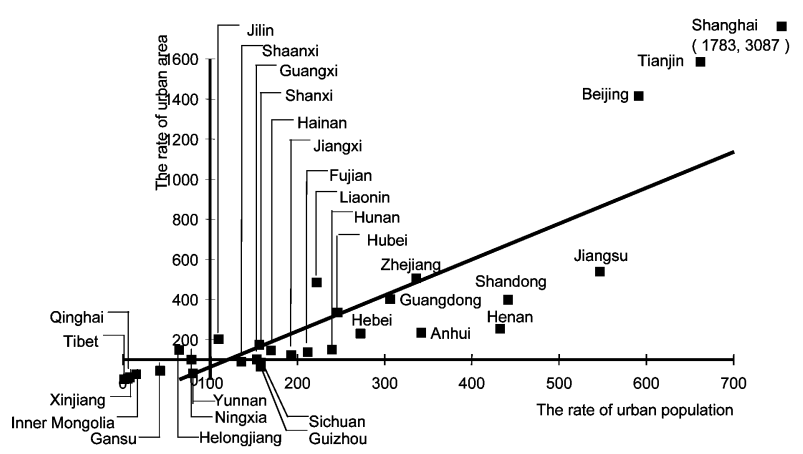

Fig. 3. Evaluation of Urbanization and Population

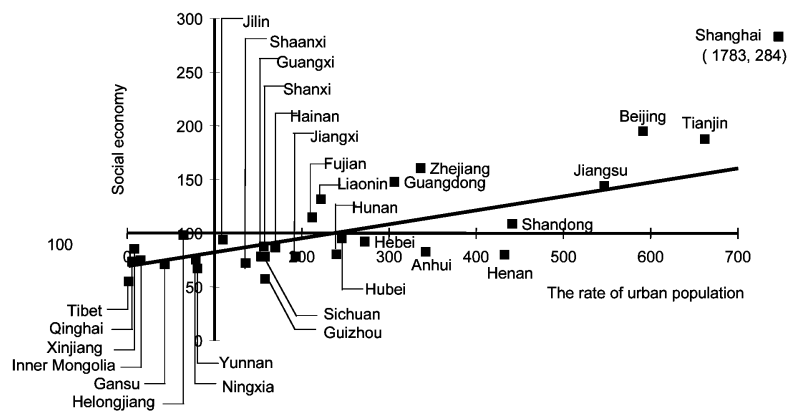

Fig.5. Evaluation of Social Economy

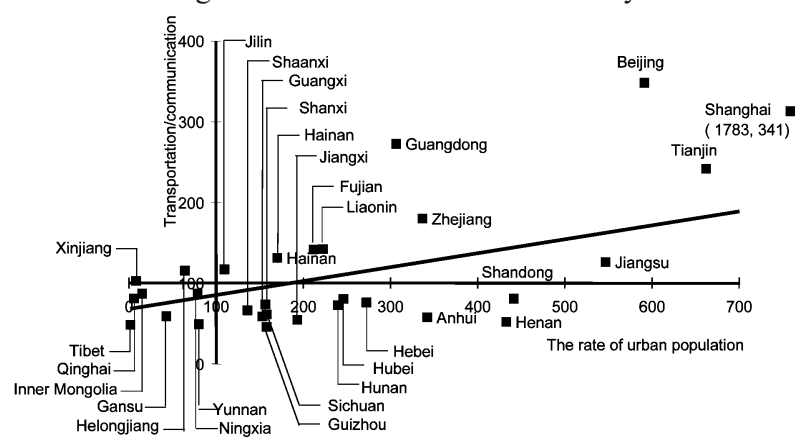

Fig.7. Evaluation of Transportation/Communication

for i Province is defined as following:

$$
S_{i}=\frac{\sum S_{i j}}{\text { Number of Basic index in i Province }}
$$

In order to obtain the classification of urbanization, the multivariate analysis is adopted in this paper. Concretely, the analysis is conducted by using two factor analyses, which are the principal components analysis and the cluster analysis, respectively.

\section{Calculation of index evaluation mark}

According to the expression defined by the foregoing paragraph, the item indexes of table 1 have been calculated by regression analysis. Those results are shown in Fig.3 Fig.9. Fig.3 is the relation between the rates of urban area (urban area/total area of one region) with the rate of urban population (urban population / total population of one region). From this figure, it can be concluded that Shanghai has 8 times the average rate of urban population of China, about $60 \%$, and 30 times the average rate of urban area of China. And also in Beijing and Tianjin, the population density exceeded

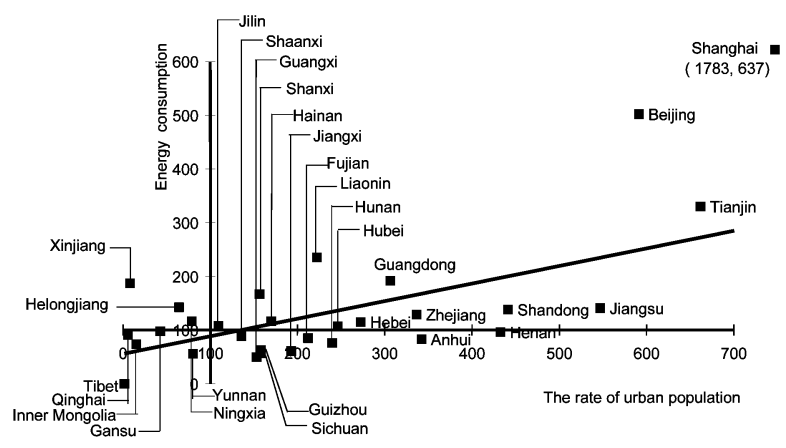

Fig.4. Evaluation of Energy Consumption

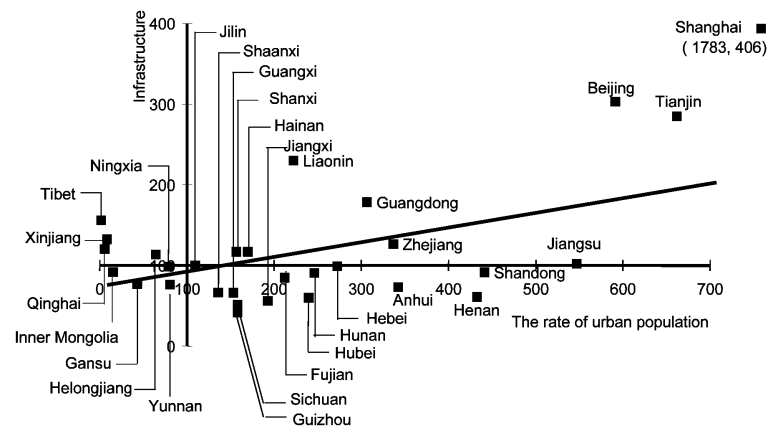

Fig.6. Evaluation of Infrastructure

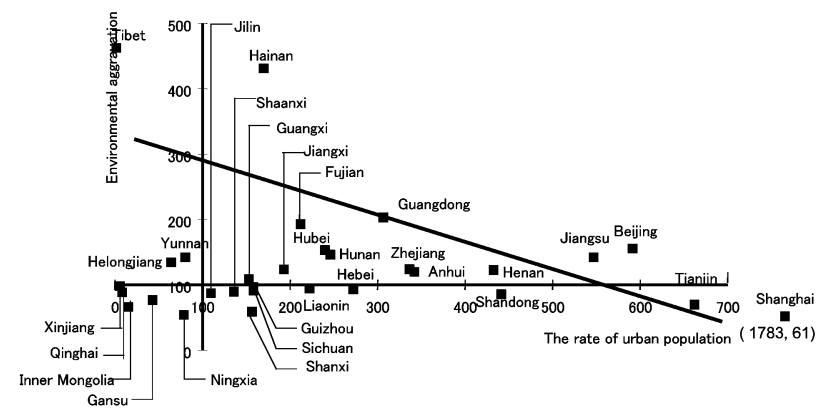

Fig.8. Evaluation of Environment

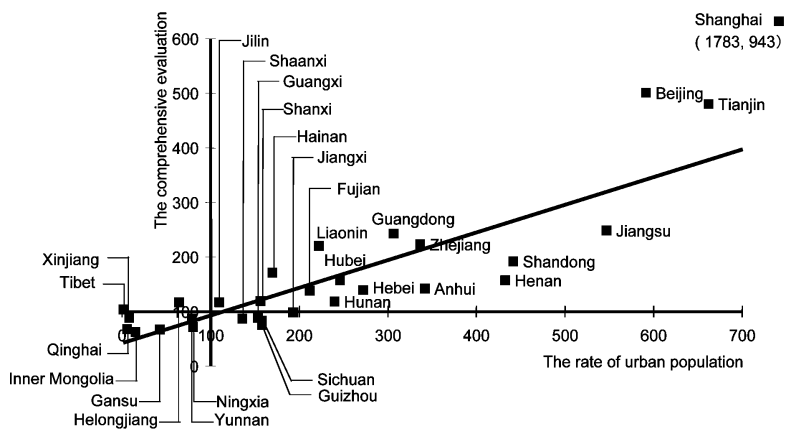

Fig.9. Comprehensive Evaluation of Urbanization

1200 humanbeing pre square kilos with about $50 \%$ of the urban population rate, and the rate of urban area is about 15 times the average rate of China. Therefore, it can be concluded that the urbanization of three direct control cities is progressing. Moreover, the rate of urban population of coastal provinces (Zhejiang, Jiangsu, Shandong and Guangdong) is about 4 to 5 times the average rate of China, so the advance of the urbanization accompanying economical rapid growth in coastal region is progressing in recent years. The evaluation of energy consumption is shown in Fig.4. According to the result, 
the evaluation mark of three direct control cities (Beijing, Shanghai, Tianjin) exceeded 300 points (the national average is 100 points), especially, Shanghai has the highest point all over country and its mark is 6 times the average of China. So it can be considered that the energy consumption has increasing tendency with the advance of urbanization. Furthermore, since Liaoning Province is the heavy industry base and Shanxi Province is the coal production base in China, these two provinces also have high-energy consumption level.

Fig. 5 shows the evaluation result of social economy. From this figure, it is proved that, except for three direct control cities (Shanghai, Beijing, Tianjin), coastal provinces, Liaoning, Shandong, Jiangshu, Zhejiang, Fujian, Guangdong, and so on, have high intensity of social economy. Therefore, the rapid growth of economy in coastal region in recent years can be concluded.

The evaluation result of infrastructure is displayed in Fig.6. Considered the province infrastructure, although the progress of urbanization is quicker in east coastal region than in the western hinterland, the mark of some index items of infrastructure is not larger than that in the western hinterland. For example, in Tibet, because the road of per capita is large, the mark of infrastructure is high. From this figure, it can also be seen that the coastal regions accompanying high-speed economy growth (such as Guangdong, Zhejiang, Jiangshu) and the heavy industry regions (such as Liaoning Province) have high evaluation mark of infrastructure.

Fig.7 shows the evaluation result of transportation/ communication. From this figure, it can be concluded that the mark of three direct control cities (Beijing, Shanghai and Tianjin) exceeded 200 points (the national average is 100 points). Except for three direct cities, the coastal regions also have the high evaluation marks of transportation/communication, such as: Liaoning, Jiangshu, Zhejiang, Fujian and Guangdong.

In this paper, some parameters, such as the park area of city, the rate of tree planting, discharge gas, $\mathrm{SO}_{2}$ and dust, have been used as item indexes of environment. It has been believed that the advance of urbanization accompanied the environmental aggravation and its tendency is shown in Fig.8. From the figure, it can be found that Shanghai and Tianjin have lower evaluation marks of environment than the average marks of China. Conversely, Tibet and Hainan have the highest the mark of environment with little contaminant discharge and more natural landscape.

The comprehensive evaluation index can be gained according to each evaluation index and their results are shown in Fig.9. From this figure, it can be concluded that Shanghai, Beijing, Tianjin and Guangdong have high evaluation mark exceeded 500 points (the national average is 100 points) with high urbanization. Moreover in the coastal region (Jiangshu, Guangdong, Zhejiang, Shandong, Liaoning), the comprehensive evaluation index is also high, and the urbanization of this region is progressing. In sum, the urbanization of eastern region is higher than that of western region.

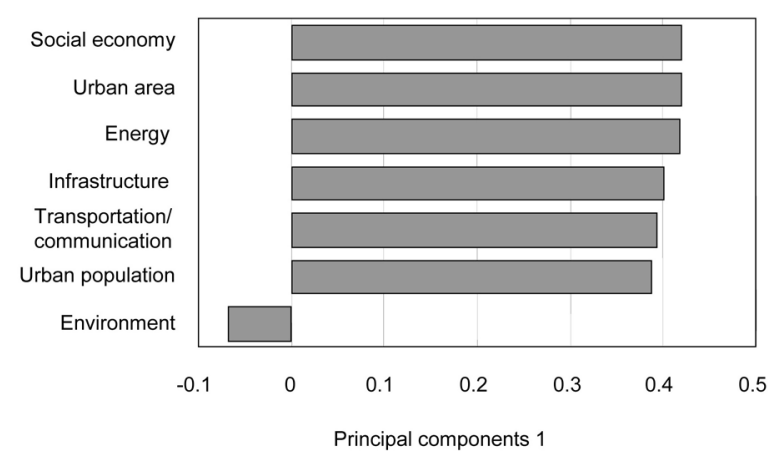

Fig.10. Principal Component of Urbanization

Table 2. The Correlation Procession

\begin{tabular}{|c|c|r|r|r|r|r|r|}
\hline & $\begin{array}{c}\text { Urban } \\
\text { area }\end{array}$ & $\begin{array}{c}\text { 佔banation } \\
\text { Energy }\end{array}$ & $\begin{array}{c}\text { Social } \\
\text { economy }\end{array}$ & $\begin{array}{r}\text { Infrastructure } \\
\text { Transportation/ } \\
\text { communication }\end{array}$ & Environment \\
\hline Rate of Urban area & 1.00 & 0.95 & 0.93 & 0.94 & 0.89 & 0.82 & -0.17 \\
Urban papulation & 0.95 & 1.00 & 0.83 & 0.88 & 0.74 & 0.70 & -0.17 \\
Energy & 0.93 & 0.83 & 1.00 & 0.91 & 0.92 & 0.89 & -0.21 \\
Social economy & 0.94 & 0.88 & 0.91 & 1.00 & 0.88 & 0.92 & -0.15 \\
Infrastructure & 0.89 & 0.74 & 0.92 & 0.88 & 1.00 & 0.88 & 0.00 \\
Transportation/ & & & & & & & \\
communication & 0.82 & 0.70 & 0.89 & 0.92 & 0.88 & 1.00 & -0.01 \\
Environment & -0.17 & -0.17 & -0.21 & -0.15 & 0.00 & -0.01 & 1.00 \\
\hline
\end{tabular}

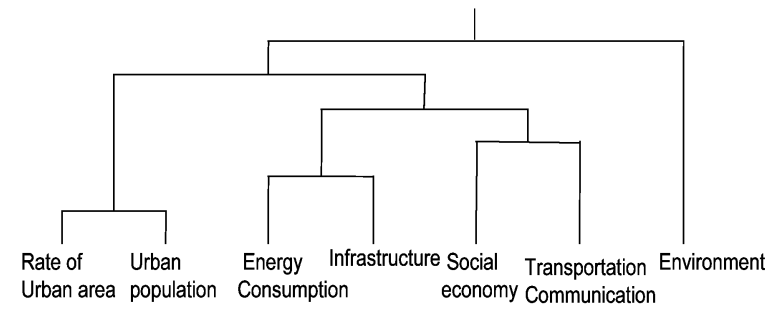

Fig.11. Cluster Analysis of Urbanization Index

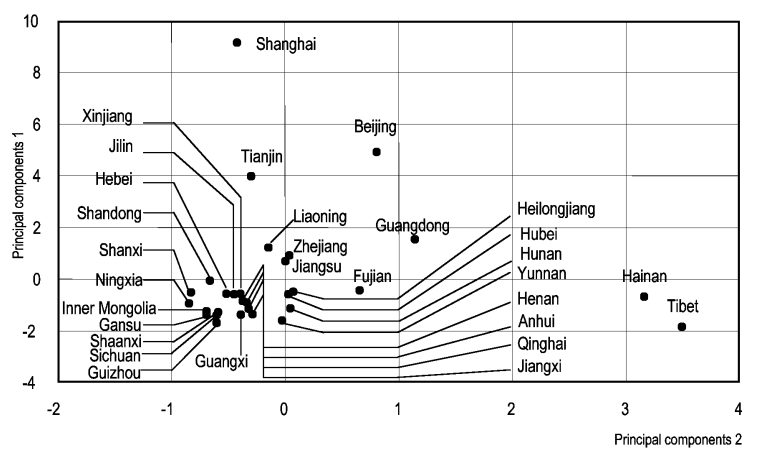

Fig.12. Principal Analysis of Urbanization

\section{Classification of urbanization}

The urban area, urban population, energy consumption, social economy, infrastructure, transportation/ communication, environment have been used as seven evaluation indexes to clear up the condition of the urbanization in China Province. Firstly, the principal components representing the progress condition of urbanization have been used as the basic indexes to analyze. The result is shown in Fig. 10 and Table 2. In Fig.10, the principal component one shows the inherent vector of the basic indexes. It can be found that the urban area, urban population, energy consumption, social economy, infrastructure, transportation/communication have increasing tendency with the advance of urbanization. However, the 


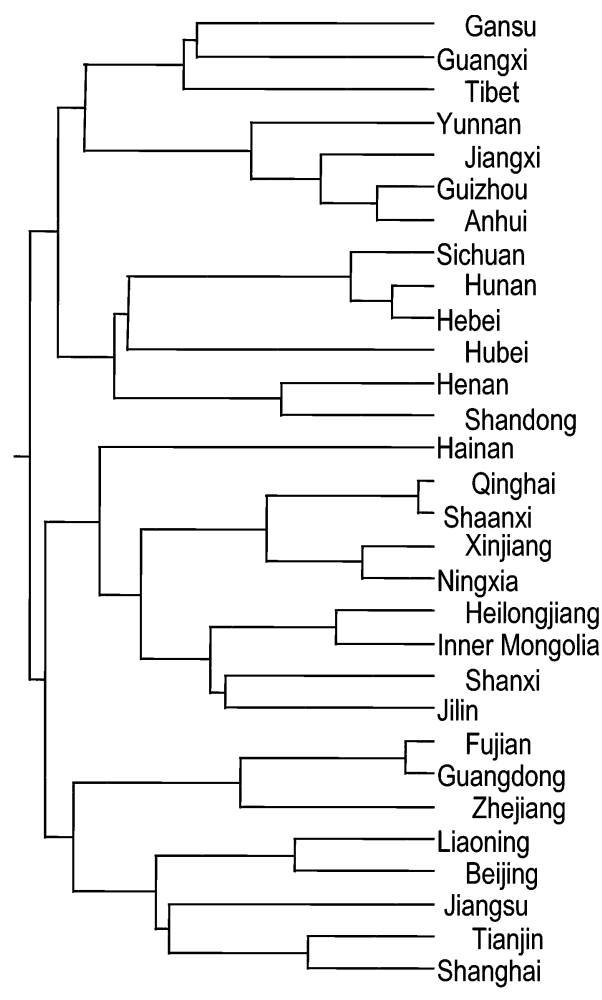

Fig.13. Cluster Analysis of Urbanization environment has been aggravated with the advance of urbanization. The correlation procession shown by table 2 also turns out the same law.

The correlation of basic indexes also can be analyzed by using cluster analysis. Fig.11 shows the four classifications of the basic indexes. Unlike other basic indexes, environment has independent effect on urbanization.

Fig. 12 shows the analysis result of the principal components analysis on each province and three direct control cities. In this figure, the principal component one expresses the evaluation axis of the advance degree of urbanization. It can be found that three direct control cities and the coastal regions have the large positive value. The principal component two displays the environmental evaluation axis. Therefore, Hainan, Tibet, which situated in the right side in Fig.12, have large environment evaluation mark.

According to the cluster analysis, all the provinces and three direct control cities can be classified four groups as Fig. 13 shown, the result is shown in Table 3. Group I included three direct control cities and the main provinces in coastal region (Jiangshu, guangdong, Zhejiang, Shandong, Liaoning, Fujian), which has high urbanization degree. In this group, the average comprehensive evaluation index is 4 times the national average, and the basic index points of urbanization are larger than the national average points; but the

Table 3. Evaluation of Urbanization Index and Classification

\begin{tabular}{|c|c|c|c|c|c|c|c|c|c|c|}
\hline No. & Province\&city & $\begin{array}{c}\text { rate of Urban } \\
\text { area }\end{array}$ & $\begin{array}{c}\text { Urban } \\
\text { population }\end{array}$ & $\begin{array}{c}\text { Energy } \\
\text { consumption }\end{array}$ & $\begin{array}{c}\text { Social } \\
\text { economy }\end{array}$ & Infrastructure & \begin{tabular}{|c|} 
Transportation \\
$/$ \\
communication
\end{tabular} & Environment & $\begin{array}{c}\text { Comprehensive } \\
\text { evaluation }\end{array}$ & Comment \\
\hline \multirow{8}{*}{ I } & Shanghai & 3087 & 1783 & 637 & 284 & 406 & 341 & 61 & 943 & \multirow{9}{*}{$\begin{array}{l}\text { Index of } \\
\text { Urbanization is } \\
\text { larger than the } \\
\text { national average }\end{array}$} \\
\hline & Tianjin & 1585 & 662 & 330 & 188 & 285 & 242 & 70 & 480 & \\
\hline & Jiangsu & 539 & 547 & 141 & 144 & 102 & 126 & 142 & 249 & \\
\hline & Beijing & 1415 & 591 & 502 & 195 & 303 & 348 & 156 & 501 & \\
\hline & Liaoning & 485 & 222 & 236 & 132 & 230 & 142 & 95 & 220 & \\
\hline & Zhejiang & 507 & 337 & 129 & 161 & 126 & 180 & 124 & 223 & \\
\hline & Guangdong & 401 & 306 & 192 & 148 & 178 & 273 & 203 & 243 & \\
\hline & Fujiang & 137 & 212 & 85 & 115 & 85 & 142 & 193 & 138 & \\
\hline \multicolumn{2}{|c|}{ Average value } & 1019 & 582 & 281 & 171 & 215 & 224 & 131 & 375 & \\
\hline \multirow{6}{*}{ II } & Shandong & 399 & 441 & 138 & 109 & 92 & 81 & 86 & 192 & \multirow{7}{*}{$\begin{array}{l}\text { Urban area and } \\
\text { population } \\
\text { increase quick. } \\
\text { The } \\
\text { infrastructure, } \\
\text { transportation,co } \\
\text { mmunication } \\
\text { need to be }\end{array}$} \\
\hline & Henan & 255 & 433 & 96 & 80 & 61 & 52 & 123 & 157 & \\
\hline & Hubei & 336 & 246 & 107 & 96 & 91 & 81 & 146 & 157 & \\
\hline & Hebei & 230 & 272 & 115 & 92 & 99 & 76 & 93 & 140 & \\
\hline & Hunan & 149 & 240 & 76 & 80 & 60 & 73 & 153 & 119 & \\
\hline & Sichuan & 87 & 158 & 57 & 78 & 52 & 61 & 91 & 83 & \\
\hline \multicolumn{2}{|c|}{ Average value } & 243 & 298 & 98 & 89 & 76 & 71 & 115 & 141 & \\
\hline \multirow{9}{*}{ III } & Jinlin & 202 & 110 & 108 & 94 & 100 & 117 & 87 & 117 & \multirow{10}{*}{$\begin{array}{l}\text { Index of } \\
\text { Urbanization is } \\
\text { the national } \\
\text { average }\end{array}$} \\
\hline & Shanxi & 174 & 156 & 167 & 88 & 117 & 74 & 59 & 119 & \\
\hline & Inner Mongolia & 27 & 15 & 74 & 75 & 92 & 87 & 67 & 62 & \\
\hline & \begin{tabular}{|l|} 
Tibet \\
\end{tabular} & 3 & 2 & 0 & 55 & 156 & 48 & 463 & 104 & \\
\hline & \begin{tabular}{|l} 
Ningxia \\
\end{tabular} & 99 & 79 & 116 & 76 & 99 & 87 & 54 & 87 & \\
\hline & Xinjiang & 13 & 8 & 187 & 85 & 133 & 103 & 88 & 88 & \\
\hline & \begin{tabular}{|l} 
Shaanxi \\
\end{tabular} & 90 & 136 & 89 & 72 & 67 & 67 & 90 & 87 & \\
\hline & \begin{tabular}{|l} 
Qinghai \\
\end{tabular} & 6 & 6 & 91 & 74 & 120 & 81 & 99 & 68 & \\
\hline & Hainan & 146 & 170 & 117 & 87 & 117 & 131 & 431 & 171 & \\
\hline & verage value & 84 & 76 & 105 & 78 & 111 & 88 & 160 & 100 & \\
\hline \multirow{7}{*}{ IV } & Anhui & 235 & 342 & 83 & 83 & 73 & 58 & 120 & 142 & \multirow{8}{*}{$\begin{array}{l}\text { Index of } \\
\text { environment is } \\
\text { higher than other } \\
\text { province. Index of } \\
\text { comprehensive } \\
\text { evaluation is } \\
\text { lower than the } \\
\text { national average. }\end{array}$} \\
\hline & Guizhou & 66 & 158 & 62 & 57 & 41 & 46 & 97 & 75 & \\
\hline & \begin{tabular}{|l} 
Jiangxi \\
\end{tabular} & 123 & 193 & 61 & 78 & 56 & 55 & 124 & 99 & \\
\hline & \begin{tabular}{|l|} 
Yunnan \\
\end{tabular} & 31 & 80 & 56 & 67 & 77 & 49 & 142 & 72 & \\
\hline & Heilongjiang & 148 & 64 & 143 & 98 & 114 & 116 & 135 & 117 & \\
\hline & \begin{tabular}{|l|} 
Guangxi \\
\end{tabular} & 101 & 153 & 50 & 78 & 66 & 59 & 109 & 88 & \\
\hline & Gansu & 44 & 43 & 98 & 71 & 77 & 59 & 77 & 67 & \\
\hline \multicolumn{2}{|c|}{ Average value } & 107 & 148 & 79 & 76 & 72 & 63 & 115 & 94 & \\
\hline
\end{tabular}




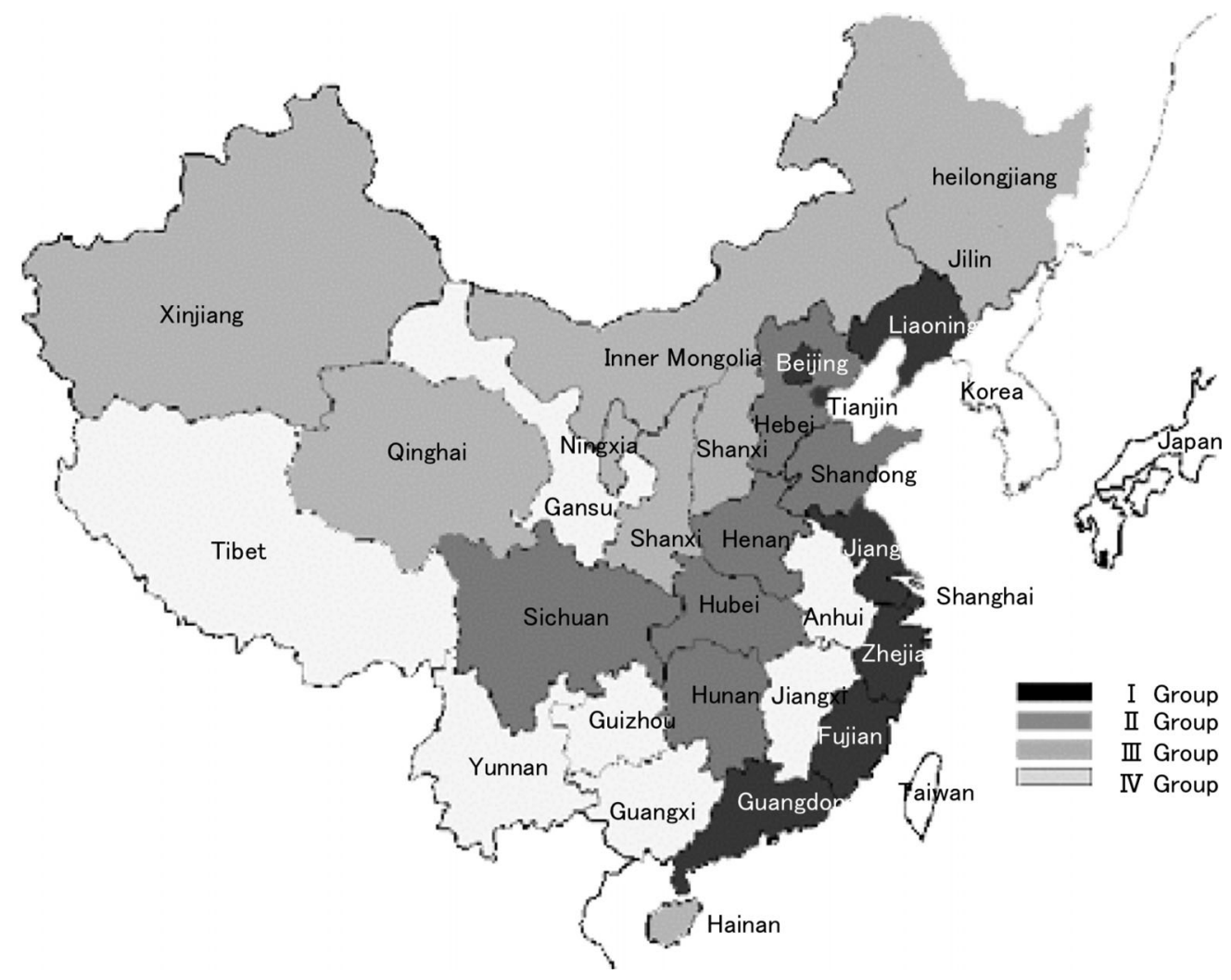

Fig.14. Classification of Urbanization in China

measurement must be carried out to against the aggravation of environment in metropolis and industry area, such as Shanghai, and Liaoning Province. Group II included the provinces in the central-western region of China (Shandong, Henan, Hebei, Hunan, Sichuan). The construction need of infrastructure and transportation/communication is very urgent to satisfy the remarkable increasing of the urban area and population in these provinces. Group III included the provinces in the north and northwest region of China. These provinces have a little high environmental evaluation value than the national average value, and the average comprehensive evaluation index of China. Group IV have the highest environmental evaluation with rich nature, but the comprehensive evaluation mark is lower than the national average value.

The classification picture of urbanization in China Province drawn according to the classification group was displayed in Fig. 14. From this figure, it can be visual displayed that the east coastal provinces have the strong tendency of urbanization, followed by the central provinces and the western province.

\section{Conclusion}

In this study, the relation of urbanization in China urban areas has been investigated with energy consumption, social economics, infrastructure, transportation and environment. The results showed that the impact of those factors on the urbanization become significant. The deep investigation is needed in clearing the effect of the local development on the urbanization.
In this paper, by using urban area and population, energy consumption, social economy, infrastructure, transportation/communication and environment as the basic indexes, the actual condition of urbanization in China Province has been evaluated. The classification of urbanization has been conducted by using the cluster analysis and the principal components analysis, and then all the regions of China have been divided into four groups. Moreover, according to the factor analysis, although the energy consumption index, the infrastructure index and the social economy index, etc. increased along with the advance of urbanization, the environmental index decreases conversely. Therefore, it is will be important to take seriously mind on environment when drafting the advance police of urbanization.

The further study is needed in clearing the actual condition of the urbanization and other factors, such energy consumption, economy, infrastructure, in the city level of each province.

\section{References}

1) Haifeng LI, Weijun GAO, Urbanization and environment situation in China: Part one Urbanization and energy use in all Provinces of China, Annual Meeting of Architectural Institute of Japan, Fukuoka, September, 1998

2) Weijun GAO, Haifeng LI, Urbanization and environment situation in China: Part two Energy use and air pollution in main cities of China" Annual Meeting of Architectural Institute of Japan, Fukuoka, September., 1998

3) National Bureau of Statistics of China, Statistics of China, 19902000 